\title{
Colposcopic Evaluation of Cervix with Persistent Inflammatory Pap Smear
}

\author{
Kamrun Nahar', Saria Tasnim², Mirza Md.Asaduzzaman ${ }^{3}$
}

\begin{abstract}
Background and Objectives: The cervical screening algorithm for benign cellular changes on the Pap smear recommends treatment of infection if indicated and a repeat Pap smear should be done in 4-6 months time. If repeat smear suggests continuation of inflammatory changes, the patient is subjected to colposcopic evaluation. During this lag time, a good number of patients in their premalignant stage may be missed or undergo malignant transformation. Recent studies advocate a repeat Pap smear if treatment of infection for 2-4 weeks does not respond and if repeat Pap smear suggests persistence of inflammatory changes, the patient should be evaluated colposcopically to determine the rate of undetected cervical intraepithelial neoplasia/dysplasia in patients with persistent inflammatory Pap smear. The present study was undertaken to that end.
\end{abstract}

Patients \& Methods: This cross-sectional study was carried out in the Department of Obstetrics and Gynaecology, Institute of Child \& Mother Health (ICMH), Dhaka, over a period of 12 months from July 2013 to June 2014. Patients with two consecutive reports of inflammatory cellular changes without atypia on Pap smears despite anti-inflammatory therapy were the study population. A total of 1456 women underwent Paps test at the above mentioned place during the study period for gynaecological problems. Of them $312(21.4 \%)$ were reported as 'inflammatory cellular changes'. After giving anti-inflammatory treatment most of them were cured leaving $128(8.8 \%)$ cases with repeat report of inflammatory cellular changes on Pap smear and hence were included in the study.

Results: The mean age of the enrolled women was $32.6 \pm 7.2$ years. Mean age of the patients at marriage and mean age at first child birth were 14.9 years (range: $12-23$ years) and 16.5 years (range: $13-26$ years) respectively. Majority (94.5\%) of the patients were multipara. Of the 128 women, $66(51.6 \%)$ were colposcopically positive for CIN. Of them over two-thirds (68.2\%) were graded as CIN-1, $25.8 \%$ as CIN-2, and $6 \%$ as CIN-3. Histological evaluation of biopsy material taken from these 66 cases revealed $25(37.9 \%)$ with abnormal cytology (3-CIN-1, 18-CIN-2 and 4 with invasive carcinoma) which accounts for $19.5 \%$ of the persistent Paps smear cases. Comparing age at marriage, age at first childbirth and parity between patients with CIN (including invasive disease) and without CIN revealed that the former group married and experienced child birth relatively earlier than the latter group ( $p=0.001$ and $p<0.001$ respectively). The average parity was also significantly higher in the CIN group.

Conclusions: A high proportion of patients with persistent inflammatory Pap smear can harbour CIN and sometimes even early stage of invasive carcinoma. So patients with persistent inflammatory cellular changes on Pap smear if does not respond to treatment, they should be subjected to a repeat smear within 2-4 weeks and if inflammatory changes continue, they should be immediately evaluated by colposcopy.

Key words: Cervix, persistent inflammatory Pap smear, colposcopy and cervical intraepithelial neoplasia.

\section{INTRODUCTION}

Cervical cancer has been the subject of several epidemiological studies since last 150 years. It is the second most common cancer in women after breast cancer. ${ }^{1-3}$ Chronic inflammation of cervix, either specific or non-specific, is thought to be one of the factors responsible for carcinogenesis. Inflammatory Pap smear is the most common

\section{Authors' Information:}

${ }^{1}$ Dr. Kamrun Nahar, Consultant (Obstetrics and Gynaecology), Institute of Child \& Mother Health Matuail, Dhaka.

${ }^{2}$ Professor Saria Tasnim, MBBS, FCPS (Obstetrics and Gynaecology), M Med, Diploma in Community Epidemiology, Institute of Child \& Mother Health Matuail, Dhaka.

${ }^{3}$ Dr. Mirza Md. Asaduzzaman, Emergency Medical Officer, Upazilla Health Complex, Debidwar, Comilla.

Address of Correspondance: Dr. Kamrun Nahar, Consultant (Obstetrics and Gynaecology), Institute of Child \& Mother Health Matuail, Dhaka. Cell: +88 01819-240802, E-mail: kamrunnaharm21@yahoo.com 
report the gynecologist receives even when the cervix appears normal. The recommended treatment for benign cellular changes on Pap smear screening is treatment of infection followed by a repeat Pap smear in 4 to 6 months time. If the inflammatory changes continue, the patient is to be subjected to colposcopy. ${ }^{4,5}$ However, this is hardly followed, especially in resource poor countries, where proper cervical screening protocol has not been established yet. Hence, a good number of patients in the premalignant stage (which may undergo malignant transformation during the lag-time) are missed. So the patients with persistent inflammatory Pap smears should be prospectively evaluated using colposcopy.

There are very few studies in the literature where the incidence of premalignant and malignant lesions was looked into in cases of inflammatory Pap smear. Inflammation can obscure few malignant cells and may result in high false negative rates which may be reduced by employing liquid based cytology. ${ }^{6}$ However, it was reported that liquid based cytology was not cost-effective for developing countries and the recent studies found no statistically significant difference of accuracy between conventional Pap test and liquid based cytology. ${ }^{7}$ The main reason for false-negative reports of cytology were found to be sampling errors, with sampling errors as high as $42.5 \%$ being suboptimal and $17.5 \%$ being inadequate for interpretation. ${ }^{8}$ McLachlan et al. $^{9}$ studied the colposcopic features and biopsy results of 102 women with persistent inflammatory Pap smears and found 19\% cases of CIN 2 or worse. Seckin et al. ${ }^{10}$ recommends colposcopic evaluation of patients with persistent inflammatory Pap smear despite therapy in any population in any part of the World. Frisch et al. ${ }^{11}$ is of the opinion that colposcopy of women with cytologic diagnosis of inflammatory epithelial changes may be a useful way to detect otherwise unrecognized cases of CIN.

In Bangladesh, every year 17,686 women are diagnosed with cervical cancer; of them 10,364 die of the disease. Although services required for carcinoma of cervix screening are available in Bangladesh, it is not practically feasible to subject all women with inflammatory Pap smear to colposcopy in our country. Therefore, this study was carried out with the aim to explore whether women with persistent inflammation on Pap smear need further evaluation with colposcopy. The data obtained from the proposed study might be helpful to define a diagnostic and management protocol for patients with persistent inflammatory cellular changes with ultimate aim of reducing morbidity and mortality from the disease.

\section{Patients \& Methods}

This cross-sectional study was carried out in the Department of Obstetrics and Gynaecology, Institute of Child \& Mother Health (ICMH), Dhaka, over a period of 12 months from July 2013 to June 2014. Patients with two consecutive reports of inflammatory cellular changes without atypia on Pap smears despite anti-inflammatory therapy were the study population. A total of 1456 married non-pregnant women (aged 18 years or more) complaining of different gynaecological problems (vaginal discharge, postcoital bleeding, intermenstrual bleeding and persistent leucorrhoea) underwent Paps test at the above mentioned place during the study period for gynaecological problems. Of them $312(21.4 \%)$ were reported as having 'inflammatory cellular changes'. After giving antiinflammatory treatment most of them were cured leaving $128(8.8 \%)$ cases with repeat report of inflammatory cellular changes on Pap smear and hence were included in the study. Colposcopic findings included in the study were acetowhite areas at squamo-columnar junction (SCJ), punctuation and mosaicism, colposcopic diagnosis and grading. Colposcoic findings were finally judged against histopathologic evaluation, the 'Gold standard' for evaluation of cervical biopsy specimen.

\section{Study procedure}

On arrival of patients at Gynae Out-patient Department (OPD) of ICMH at the age of ${ }^{3} 18 \mathrm{yrs}$ with the complaints of excessive vaginal discharge, post coital bleeding etc, they were 
advised for Pap's smear. If Pap's smear test exhibited inflammatory cellular changes without atypia, the patient received treatment of infection with Doxcycline daily for 14 days or metronidazole or ornidazole or third generation cepholosporines and povidone iodine-containing suppositories for 7 days or both and a repeat Pap's smear was performed after 14 days. If the inflammatory changes persist, the patient was subjected to colposcopy. If colposcopic evaluation revealed any abnormalities then biopsy was taken (the detail of the colposcopic procedure is given in the box below). The specimen was fixed with formalin and was sent to histopathology for confirmation of diagnosis.

Colposcopic procedure: To perform colposcopic examination, the cervix was first cleaned by $0.9 \%$ saline solution and visualized at low magnification and pathologies of vasculature were investigated under green filter. Then 5\% acetic acid was applied and after waiting 60 seconds cervix was visualized under low and high magnification. Aceto-white areas and atypical vasculature were determined. Visual inspection with acetic acid (VIA) positivity was considered if there were acetowhite areas in the transformation zone close to squamo-columnar junction or the os. Iodine negative areas were determined at cervix by applying lugol solution. A biopsy was performed from aceto-white, mosaic, iodine-negative areas and from punctuations, atypical vasculatures, and erosions. When these pathological findings were not determined a blind punch biopsy was performed from four quadrants of cervix and biopsy specimens were sent to pathology laboratory inside formal for histopathpologic examination.

\section{Statistical analysis}

Data were processed and analysed using computer software SPSS (Statistical Package for Social Sciences). The test statistics used for analysis of data were Chi-square Test (for comparison of categorical data between groups), Student's t-Test (for comparison of continuous data between groups). For any analytical test the level of significance was set at 0.05 and $p$-value $<0.05$ was considered significant.

\section{RESULT}

Nearly half (48.5\%) of the study subjects were between 20 - 30 years with mean age of the patients being 32.6 (range: 18 - 48) years. Mean age of the patients at marriage was 14.9 years (range: 12-23) and the mean age at first child birth was 16.5 years (range: 13-26). In terms of parity majority $(94.5 \%)$ of the patients was multipara (Table I). Contraceptive behavior shows that over two-thirds (68\%) used oral contraceptives. In about $15 \%$ cases their husbands used condom and only $2.3 \%$ adopted

TABLE I. Distribution of respondents by their age $(n=128)$

$\begin{array}{|lcc|}\text { Age (years)* } & \text { Frequency } & \text { Percentage } \\ <20 & 4 & 3.1 \\ 20-30 & 62 & 48.4 \\ 30-40 & 50 & 39.1 \\ { }^{3} 40 & 12 & 9.4\end{array}$

$*$ Mean age $=(32.6 \pm 7.2)$ years; range $=(18-48)$ years

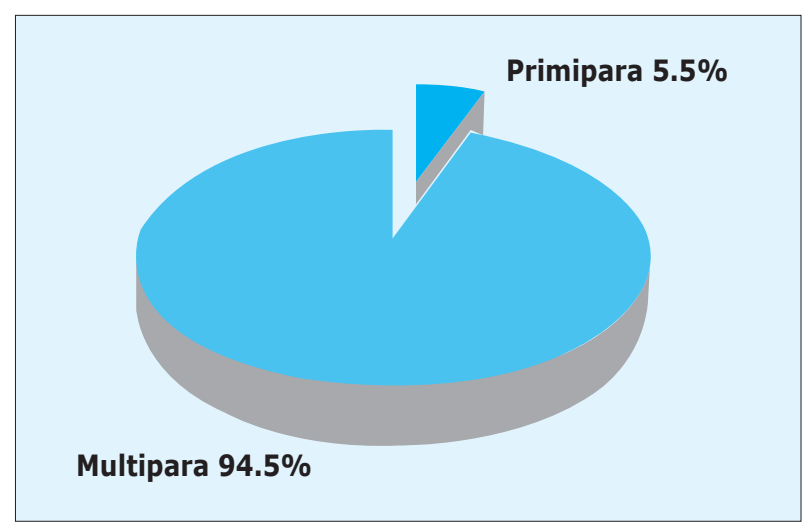

FIGURE 1: Distribution of respondents by their Parity $(n=128)$

other protection measures (Fig. 2). Almost all patients complained of persistent leucorrhoea 


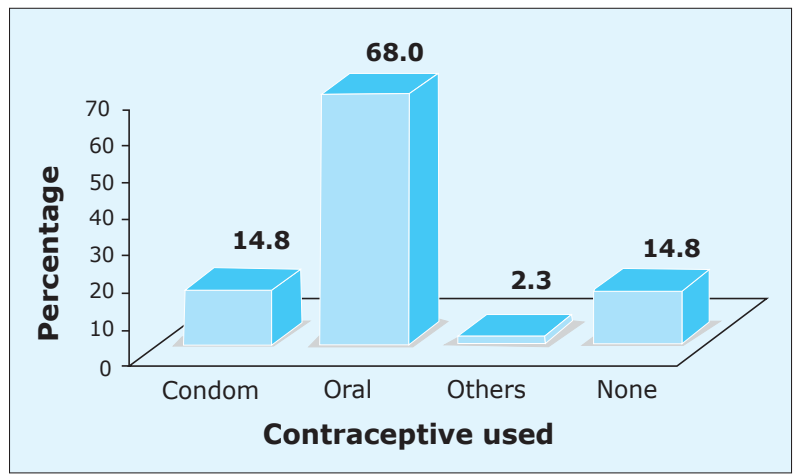

FIGURE 2: Distribution of respondents by use of contraceptive $(n=128)$

TABLE II. Distribution of respondents by their reproductive life-events $(n=128)$

$\begin{array}{lcc}\text { Reproductive life-events } & \text { Mean } \pm \text { SD } & \text { Range } \\ \text { Age at marriage }(y r s) & 14.9 \pm 1.7 & 12-23 \\ \text { Age at first child birth (yrs) } & 16.5 \pm 1.9 & 13-26\end{array}$

not responding to antibiotics (99.2\%). Vaginal discharge $(97.7 \%)$ was the predominant complain followed by postcoital bleeding (16.4\%) and intermenstrual bleeding $(3.1 \%)$. Most of the cervices were broad (78.1\%) and cervical erosion was found in $13.3 \%$ cases. Nearly $60 \%$ of uterus was of normal size and $41.4 \%$ bulky. Almost all of the uteri exhibited free fornix (Table III). PAP-smear test revealed bacterial vaginosis and Trichomonasvaginalis infection in $2.3 \%$ and $6.3 \%$ cases respectively (Table IV). Colposcopic examination showed squamocolumnar junction $(\mathrm{SCJ})$ clearly in all cases. Visual inspection with acetic acid (VIA) exhibited about $25 \%$ SCJ as light acetowhite, $72.7 \%$ as dense acetowhite and $3.1 \%$ as mosaic appearance. Of the 128 women, $66(51.6 \%)$ were colposcopically positive for CIN. Of them over two-thirds (68.2\%) were graded as CIN-1, $25.8 \%$ as CIN-2, and $6 \%$ as CIN-3. Histological evaluation of biopsy-material taken from these 66 cases revealed 25(37.9\%) with abnormal cytology (3-CIN-1, 18-CIN-2 and 4 with invasive carcinoma) which accounts for $19.5 \%$ of the persistent Paps smear cases (Table V). Of the 25 histopathologically confirmed cases, $72.2 \%$ had CIN-2, $12 \%$ had CIN-1 and the rest $16 \%$ had invasive carcinoma (Table VI). As potential risk factors were compared between patients with and without positive histopathological findings, it was found that early age at marriage and early child-birth and high parity were significantly associated with development of cervical intraepithelial neoplasia or dysplasia $(\mathrm{p}=0.001, \mathrm{p}<0.001$ and $\mathrm{p}=$ 0.006 respectively) (Table VII).

\section{TABLE III. Distribution of subjects by their clinical characteristics $(n=128)$}

$\begin{array}{lcc}\text { Clinical characteristics } & \text { Frequency } & \text { Percentage } \\ \text { History } & & \\ \text { Persistent leucorrhoea not } & & \\ \text { responding to a antibiotics } & 127 & 99.2 \\ \text { Vaginal discharge } & 125 & 97.7 \\ \text { Post-coital bleeding } & 21 & 16.4 \\ \text { Intermenstrual bleeding } & 4 & 3.1 \\ \text { Perspeculum examination } & & \\ \text { Cervix } & & \\ \quad \text { Broad } & 100 & 78.1 \\ \quad \text { Hypertrophy } & 16 & 12.5 \\ \quad \text { Normal } & 12 & 9.4 \\ \text { Cervical erosion } & 17 & 13.3 \\ \text { P/V findings } & & \\ \text { Size of uterus } & & \\ \quad \text { Bulky } & \\ \quad \text { Normal } & 53 & 41.4 \\ \text { Fornix } & \text { Free } \\ \quad \text { Thickened } & 75 & 58.6 \\ \quad & 127 & 99.2 \\ & 1 & 0.8\end{array}$

\section{TABLE IV: Distribution of subjects by their Pap smear} findings $(n=128)$

$\begin{array}{lcc}\text { Pap smear findings } & \text { Frequency } & \text { Percentage } \\ \text { Bacterial vaginosis } & 3 & 2.3 \\ \text { Trichomonasvaginalis } & 8 & 6.3\end{array}$


TABLE V: Distribution of subjects by their colposcopic evaluation $(n=128)$

\begin{tabular}{|c|c|c|}
\hline Colposcopic evaluation & Frequency & Percentage \\
\hline $\begin{array}{l}\text { Squamo-columnar } \\
\text { junction (SCJ) seen clearly } \\
\text { VIA with } 5 \% \text { acetic acid }\end{array}$ & 128 & 100.0 \\
\hline Acetowhite Light & 31 & 24.2 \\
\hline Acetowhite Dense & 93 & 72.7 \\
\hline Mosaicism & 4 & 3.1 \\
\hline \multicolumn{3}{|l|}{ Colposcopic comment $(n=128)$} \\
\hline Positive & 66 & 51.6 \\
\hline Negative & 62 & 48.4 \\
\hline \multicolumn{3}{|l|}{ Colposcopic Grading $(n=66)$} \\
\hline CIN-1 & 45 & 68.2 \\
\hline CIN-2 & 17 & 25.8 \\
\hline CIN-3 & 4 & 6.0 \\
\hline
\end{tabular}

TABLE VI. Patients stratified by histopathological comment and grading $(n=66)$

$\begin{array}{lll}\begin{array}{l}\text { Histopathological } \\ \text { comment and grading }\end{array} & \text { Frequency } & \text { Percentage } \\ \begin{array}{l}\text { Comment( } \mathbf{n = 6 6 )} \\ \quad \text { Positive }\end{array} & 25 & \\ \quad \text { Negative } & 41 & 62.1 \\ \text { Grading }(\mathbf{n = 2 5 )} & & \\ \quad \text { CIN-1 } & 3 & 12.0 \\ \text { CIN-2 } & 18 & 72.0 \\ \text { Invasive carcinoma } & 4 & 16.0\end{array}$

TABLE VII. Association between CIN and putative risk factors

\begin{tabular}{|lccc|}
\hline Suspected risk factors & \multicolumn{3}{c}{ Histopathology comment } \\
& $\begin{array}{l}\text { Positive } \\
(\mathbf{n = 2 5 )}\end{array}$ & $\begin{array}{l}\text { Negative } \\
(\mathbf{n = 4 1 )}\end{array}$ & p-value \\
\hline Age* (yrs) & $33.1 \pm 7.3$ & $30.8 \pm 7.5$ & 0.170 \\
Age at marriage* (yrs) $^{*}$ & $13.6 \pm 1.2$ & $14.6 \pm 1.1$ & 0.001 \\
Age at first child birth* (yrs) & $14.9 \pm 1.2$ & $16.3 \pm 1.1$ & $<0.001$ \\
Parity* & $3.0 \pm 0.9$ & $2.4 \pm 0.8$ & 0.006 \\
Contraceptive used\# & & & \\
Condom & $2(28.6)$ & $5(71.4)$ & \\
Oral contraceptive & $21(38.9)$ & $33(61.1)$ & \\
Other & $1(100.0)$ & $0(0.0)$ & 0.531 \\
None & $25(37.9)$ & $41(62.1)$ & \\
\hline
\end{tabular}

Figures in the parentheses denote corresponding percentage

*Data were analysed using Unpaired $t$-Test and were presented as mean $\pm S D$. \#Data were analysed using Chi-square (?2) Test.

\section{Discussion}

Pap smear test is a major screening test for early diagnosis and treatment of cervix cancer. Inflammation on Pap smear is considered a relatively benign finding. However, due to the low sensitivity and high false negative rate (as high as $20 \%$ ) of Pap smear, there is a possibility that an inflammatory Pap smear may miss cervical premalignant changes and in rare cases malignant changes as well. Since the incidence of inflammation on Pap smear is very high $(14 \%$ $19 \%), 9,10,12,13$ it may not be possible to subject all patients with inflammation to colposcopy or HPV DNA testing. Keeping this view in mind, this study was designed to evaluate whether persistent inflammatory changes on Pap smear could be the first indication of premalignant changes in the cervix and whether further evaluation by colposcopy would help to triage these women.

In the present study a total of 1456 women underwent Pap test during the study period for gynaecological problems like vaginal discharge, postcoital bleeding, intermenstrual bleeding and leucorrhoea. Of them $312(21.4 \%)$ were reported as having 'inflammatory cellular changes'. Antiinflammatory treatment given to these patients cured most of them leaving $128(8.8 \%)$ cases with a repeat report of inflammation on Pap smear which also compares well with the study of Bhutia et al. ${ }^{14}$ Similar results were reported by Seckin et al. ${ }^{10}$ But the prevalence was lower than that reported by Sandmire et al ${ }^{15}(35.1 \%)$. The prevalence of inflammatory Pap smear in various Indian studies is reported to vary between $70 \%$ and $80.5 \% .{ }^{12,16}$ However, in a recent study the reported prevalence was lower $(24.3 \%)$ is quite consistent with the findings of the present study.

Among the persistent inflammatory Pap smear cases, 66(51.6\%) were colposcopically positive for CIN and biopsymaterial histologically, exhibited abnormal cytology in $25(37.9 \%)$ cases (CIN-1 12\%, CIN-2 72\% and invasive carcinoma $16 \%$ ) which accounts for $19.5 \%$ of the 128 women 
with persistent Paps smear included in the study. In another study, out of the 30 women with persistent inflammatory Pap smear 16(53.3\%) women had abnormal colposcopic findings and CIN was found in 5 of these women meaning $16.3 \%$ women with persistent inflammatory Pap smear were harboring CIN. Various studies have found the possibility of CIN with a report of persistent inflammatory smear to range from 18 to $35 \% .9,10$

The mean age of the women with persistent inflammatory Pap smear was $32.6 \pm 7.2$ years which is fairly comparable with the findings of Bhutial et al ${ }^{14}$ ( $30.43 \pm 6.1$ years). Comparison of age at marriage, age at first childbirth and parity between patients with CIN (including invasive disease) and without CIN revealed that the former group married and experienced child birth significantly earlier than the latter group ( $p$ $=0.001$ and $p<0.001$ respectively). The average parity was also significantly higher in the CIN group than that in women without CIN. Bhutiaet al. ${ }^{14}$ reported that mean age at marriage was $18.9 \pm 2.6$ years among women with persistent inflammatory smear while that with the women with CIN was $16.8 \pm 2$ years $(p=0.05)$. The mean parity was also higher in the former group $(p>0.05)$ thus favouring the findings of the present study.

According to various studies, ASCUS (atypical squamous or glandular cells of undetermined significance) on Pap smear has a $10-20 \%$ chance of harboring CIN. ${ }^{17,18}$ This is the reason why we triage women with ASCUS on Pap smear with either repeat cytology, HPV DNA testing, or colposcopy. ${ }^{19}$ Our study has shown a sizable proportion of women (about 20\%) with persistent inflammation on Pap smear could be harboring CIN. Moreover, the incidence of CIN and invasive carcinoma in women with persistent inflammatory Pap smears over just 2 weeks was found to increase to $20.6 \%$ and $0.7 \%$, respectively, in a study by Dasari et al. ${ }^{5}$ Hence, by waiting for a longer period of time before repeating the Pap smear may lead to a delay in diagnosis of CIN in a high percentage of cases.

The mechanism involved in the transformation of chronic inflammatory cells to carcinogenic cells is not clear. However, persistent inflammation is thought to increase cellular turnover, especially in the epithelium, and provides a selection pressure that results in the emergence of cells that are at a high risk for malignant transformation. ${ }^{20}$ Hence, all women with persistent inflammation on Pap smear should be subjected to further evaluation. One must not see a report of inflammation on Pap smear in isolation and ignore it as being absolutely insignificant. Following treatment with antibiotics, a repeat Pap smear is needed in 2-4 weeks apart and if it persists in any patient, she must be evaluated further by colposcopy.

\section{Conclusion}

On the basis of the findings of the study, it can be concluded that patients with persistent inflammatory Pap smear can harbor a high proportion CIN and sometimes even early stage of invasive carcinoma. Pap smear report of persistent inflammatory cellular changes should not be considered as a variant of normal, specially when it does not respond to adequate recommended therapy. Such patients must be referred to further evaluation by colposcopy. A large-scale study should be conducted to validate the findings of the present study.

\section{REFERENCES}

1. Elkas J, Faries-Einser R. Cancer of the uterine cervix. Curr Opin Obstet Gynaecol 1998;10:47-50.

2. Achour M, Zeghal D. Cervical Cancer in Women with Inflammatory Pap Smears. J Cancer Therapy 2014;5:82-90. Available at:http://www.scirp.org/ journal/jct\&http://dx.doi.org/10.4236/=jct.2014. 51011

3. Lawley TB, Lee RB, Kapela RR. The significance of moderate and severe inflammation on classI Papanicolaousmear. Obstet Gynaecol 1990;76:997-9. 
4. ACOG (The American College of Obstetricians \& Gynecologists). Practice Bulletin. clinical management guidelines for Obstetrician and Gynecologist Cervical Cytology screening. Obstet Gynecol 2003;102:417-27.

5. Dasari P, Rajathi S, Kumar SV. Colposcopic evaluation of persistent inflammatory Pap smear: A prospective analytical study. Cytojournal 2010;7:16.

6. Marchand L, Van Dinter M, Mundt M, Dingel W, Klein G. Current cervical cancer screening practices of Dane Country, Wsconsin Primary care clinicians. WMJ 2003; 102:3540.

7. ACOG Committee on Practice Bulletins Gynecology. Cervical cytology screening. ACOG Practice Bulletin no. 109. Obstet Gynecol 2009;114(6):1409-20.

8. Vassilakos P. Management of Suboptimal Cytologic smears: Persistent inflammatory smears. Acta Cytol $1998 ; 42: 1481$

9. McLachlan N, Patwardhan JR, Ayer B, Pacey NF. Management of suboptimal cytological smears. Acta Cytol 1994;38:531-6.

10. Seckin NC, Turban NO, Ozmen S, Ersan F, Avsar F, Ustin $H$. Routine evaluation of patients with persistent inflammatory cellular changes on Pap smear. Int $J$ Gynaecol Obstet 1997;59:25-9.

11. Frisch LE, Parmar H, Buckley LD, Chalem SA. Colposcopy of patients with Cytologic Inflammatory epithelial changes. Acta Cytol 1990;34:1335.

12. Parashari A, Singh V, Gupta MM, Satyanarayana L, Chattopadhya D, Sodhani P, et al. Significance of inflammatory cervical smears. APMIS 1995;103:273-8.
13. Eckert LO, Koutsky LA, Kiviat NB, Krone MR, Stevens $\mathrm{CE}$, Eschenbach DA. The inflammatory Papnicolaou smear: What does it mean? Obstet Gynecol 1995;86:360-6.

14. Bhutia K, Puri M, Gami N, Aggarwal K, Trivedi SS. Persistent inflammation on Pap smear: Does it warrant evaluation. Indian J Cancer 2011;48(2):220-22.

15. Sandmire HF, Austin SD, Bechtel RL. Experience with 40,000 Papanicolaou smears. Obstet Gynecol 1976; 48:56-60.

16. Mali BN, Joshi JU, Bhave GG, Wagle UD. Cervical cytology in prostitutes of Bombay (India). Genitourin Med 1992; 68:62-3.

17. Wright TC, Sun XW, Loulos J. Comparison of management algorithms for the evaluation of women with low-grade cytologic abnormalities. Obstet Gynecol $1995 ; 85: 202-10$

18. Lonky NM, Navarre GL, Saunders S, Sadeghi M, WoldeTsadik G. Low-grade Papanicolaou smears and the Bethesda system: A prospective cytohistopathologic analysis. Obstet Gynecol 1995;85:716-20.

19. Wright TC, Massad LM, Dunton CJ, Spitzer M, Wilkinson EJ, Solomon D, et al. Consensus guidelines for the management of women with abnormal cervical cancer screening tests. Am J Obstet Gynecol 2007;197:34655.

20. Moss SF, Blaser MJ. Mechanisms of Disease: Inflammation and origins of cancer. Nat Clin Pract Oncol 2005;2:907. 